\title{
Research of the detoxification properties of the preparation phytoglinol on the heat stress model
}

\author{
Marina Semenenko, ${ }^{1,}$, Olga Lanets $^{1}$, Andrey Abramov ${ }^{1}$, Elena Kuzminova ${ }^{1}$, and \\ Inna Zholobova ${ }^{2}$ \\ ${ }^{1}$ Krasnodar Research Center for Animal Husbandry and Veterinary Medicine, 350055, \\ Pervomaiskaya st. 4, Krasnodar, Russian Federation \\ ${ }^{2}$ Kuban State Agrarian University named after I.T. Trubilin, 350044, Kalinina st. 13, Krasnodar, \\ Russian Federation
}

\begin{abstract}
The article discusses the possibility of using a new veterinary preparation phytoglinol to improve the quality of meat and dairy raw materials in the context of solving the problems of food security in the Russian Federation. An experiment conducted on laboratory animals to simulate heat stress revealed pronounced detoxification and stresscorrecting properties of the preparation. The obtained results indicate that the new preparation phytoglinol not only ensures the correction of metabolic homeostasis under heat stress conditions, but also helps to weaken endotoxicosis, reduce the level of lipid peroxidation products in the body of experimental animals, thereby exhibiting a pronounced antitoxic and antioxidant effect.
\end{abstract}

\section{Introduction}

The food security of our country is characterized by three leading food subcomplexes: grain, meat and dairy production. They account for more than $75 \%$ of all production $[1,2]$. The way of intensification of production processes in the domestic livestock industry increased the amount of gross product, but the quality of livestock raw materials deteriorated, mainly because of the increased constant load on the body of the main object of obtaining the product - a farm animal.

Thereby, improving the quality of meat, milk and dairy products, increasing their safety, preservation of the composition, useful properties, eliminating losses at all stages of production and sale are relevant directions in solving the problems of food security of the Russian Federation, as well as ensuring a full and healthy nutrition of the country's population $[3,4]$.

The quality of meat and milk cannot be improved during processing; in the best case it can be only stabilized (its deterioration is suspended or slowed down). The quality control system for meat and milk should focus on the technological processes of their production, namely, on the complex of veterinary and zootechnical measures aimed at raising healthy

\footnotetext{
* Corresponding author: sever291@mail.ru
} 
livestock at livestock enterprises [5, 6]. An important part of these measures can be new pharmacological agents aimed at eliminating the undesirable consequences of intensive animal husbandry, manifested in the form of disorders of homeostasis, chronic toxicosis and decrease in the natural resistance of the organism of productive animals [7].

Among the reasons contributing to the occurrence of chronic intoxication, pathological changes in the metabolism of animals, are various negative environmental factors that cause serious disturbances because of the development of stress damage to the life support organs [8]. In this case, by modeling a certain stressful effect in experiments on laboratory animals, it is possible to reveal the patterns of pathology development, starting from the moment of interaction of the stress factor with the body until its outcome, and also to determine the relationship between damage and the functional state of various organs and systems of the body under the influence of the stress factor with subsequent adequate pharmacological correction of the adaptive abilities of the animal [9].

Based on this, the aim of this experiment was to evaluate the stress-corrective and antitoxic effect of the preparation phytoglinol on the body of white rats subjected to prolonged exposure of high temperatures and high air humidity.

\section{Materials and Methods}

The experiment was carried out on 45 white nonlinear male rats with an average body weight of 260-300 g, divided into five groups. The first group $(\mathrm{n}=5)$ - intact healthy animals, the second, third, fourth groups $(\mathrm{n}=10)$ - experimental animals, the fifth group $(\mathrm{n}$ $=10)-$ control.

The scheme of the experiment involved the study of various doses and time intervals of phytoglinol use on the background of high temperatures. In this connection, the rats were injected intramuscularly into the posterior femoral muscle groups with the preparation in the dosages presented in Table 1 in compliance with the rules of asepsis and antiseptics.

Table 1. Scheme of the experiment on modeling heat stress in laboratory animals using the preparation phytoglinol

\begin{tabular}{|l|c|c|}
\hline \multicolumn{1}{|c|}{ Group, $\mathbf{n}$} & Multiplicity of injection & $\begin{array}{c}\text { Preparation dose, } \\
\text { ml / } \\
\text { animal }\end{array}$ \\
\hline Intact, $\mathrm{n}=5$ & Without the use of preparation & - \\
\hline $\begin{array}{l}1 \text { Experimental, } \\
\mathrm{n}=10\end{array}$ & $\begin{array}{c}\text { Phytoglinol for 5 days, once per day before the } \\
\text { experiment, 1 hour before heat treatment and within 4 days of } \\
\text { heat treatment } \text { (9 days in total) }\end{array}$ & $0.5 \mathrm{ml}$ \\
\hline $\begin{array}{l}2 \text { Experimental, } \\
\mathrm{n}=10\end{array}$ & $\begin{array}{c}\text { Phytoglinol for 5 days, once per day before the } \\
\text { experiment, 1 hour before heat treatment and within 4 days of } \\
\text { heat treatment (9 days in total) }\end{array}$ & $0.25 \mathrm{ml}$ \\
\hline $\begin{array}{l}3 \text { Experimental, } \\
\mathrm{n}=10\end{array}$ & $\begin{array}{c}\text { Phytoglinol during the experiment } 1 \text { hour before the heat } \\
\text { treatment (only 4 days) }\end{array}$ & $0.5 \mathrm{ml}$ \\
\hline $\begin{array}{l}\text { Control, } \\
\mathrm{n}=10\end{array}$ & $\begin{array}{c}\text { Saline within 5 days before the experiment, 1 hour before } \\
\text { heat treatment and within 4 days of heat treatment (9 days in } \\
\text { total) }\end{array}$ & $0.5 \mathrm{ml}$ \\
\hline
\end{tabular}

Intact animals were taken into the experiment to control the physiological state of the body of animals that were not subjected to the heat treatment. The rats of the control group were intramuscularly injected with saline in a dose of $0.5 \mathrm{ml}$ per animal.

The animals were kept in boxes on a soft bedding made of sawdust, feeding was carried out 2 times per day with balanced in vitamins and minerals cereal food, fruits and dried fruits and automatic drinkers were equipped for drinking.

The heat stress was reproduced by thermally treating the animals in a specially equipped climatic chamber, for which every day for four days the control and experimental groups of 
rats were placed by a group method in special boxes with equipped holes for oxygen supply for 20 minutes in a chamber at the temperature of $+40{ }^{\circ} \mathrm{C}$ and $80-85 \%$ humidity [10].

The severity of the stress reaction of the animal organism and the effectiveness of pharmacological correction were determined by the change in the gravimetric parameters of the body, thermoregulation, the level of the lipid peroxidation products, and the development of endogenous intoxication products in the rat organism. The weighing of the experimental animals was carried out at the time of selection of individuals into groups, as well as one hour before the heat treatment and one hour after it.

Thermometry was performed rectally with an electronic thermometer before placing the animals in the boxes, 10 minutes before the experiment and 30 minutes after the thermometer procedure.

Blood for laboratory studies was taken immediately after the end of the experiment after the euthanasia of the animals under thiopental anesthesia $(50 \mathrm{mg} / \mathrm{kg})$ by taking blood from the heart until it was stopped. In addition, a pathological autopsy of rats was carried out, followed by an external examination of the organs and their histological examination. Biochemical studies of blood serum were carried out on an automatic analyzer - Vitalab Selectra Junior with software version 1.0. (manufactured by Vital Scientific N. V. Netherlands) using reagents from ELITech Clinical Systems (France) and Analyticon biotechnologies AG (Germany).

The assessment of the parameters of the lipid peroxidation system and antioxidant defense system was carried out in accordance with the methodological recommendations of All-Russian Scientific Research Veterinary Institute of Pathology, Pharmacology and Therapy (1997), to study the processes of lipid peroxidation and the antioxidant defense system in animals. The level of endogenous intoxication was determined by the method of N.I. Gabrielyan and V.I. Lipatova (1984) at different wavelengths of the spectrophotometer.

Statistical processing of the results was carried out using the statistical software packages Microsoft Excel XP and Statistical for Windows.

\section{Results}

The data obtained during the experiment showed that prolonged heat exposure on animals leads to a decrease in body weight characteristic of the stress response (Table 2).

Table 2. Gravimetric changes in the body weight of experimental animals under the heat stress $(\mathrm{M} \pm \mathrm{m})$

\begin{tabular}{|c|c|c|c|c|c|c|c|}
\hline \multirow{3}{*}{ Groups } & \multicolumn{5}{|c|}{ Body weight, $\mathrm{g}$} & \multicolumn{2}{|c|}{ Body weight gain } \\
\hline & \multirow{2}{*}{$\begin{array}{c}\text { Before the } \\
\text { beginning of } \\
\text { the } \\
\text { experiment } \\
\end{array}$} & \multicolumn{4}{|c|}{ Heat treatment } & \multirow{2}{*}{$\begin{array}{l}\text { For the } \\
\text { research } \\
\text { period, g }\end{array}$} & \multirow{2}{*}{$\begin{array}{c}\text { In } \% \\
\text { to } \\
\text { intact }\end{array}$} \\
\hline & & 1 day & 2 day & 3 day & 4 day & & \\
\hline Intact & $275.1 \pm 9.3$ & $279.7 \pm 9.1$ & $281.2 \pm 8.6$ & $284.6 \pm 8.4$ & $286.5 \pm 8.1$ & $11.4 \pm 0.9$ & 100.0 \\
\hline 1 Experimental & $284.3 \pm 7.6$ & $286.4 \pm 7.5$ & $287.5 \pm 6.9$ & $286.8 \pm 7.2$ & $287.4 \pm 7.7$ & $3.1 \pm 0.6$ & 27.2 \\
\hline 2 Experimental & $266.6 \pm 10.3$ & $271.4 \pm 9.5$ & $273.2 \pm 9.4$ & $272.8 \pm 9.8$ & $271.1 \pm 10.0$ & $4.5 \pm 0.3$ & 39.5 \\
\hline 3 Experimental & $277.1 \pm 7.1$ & $284.6 \pm 6.9$ & $280.4 \pm 7.1$ & $281.0 \pm 7.2$ & $282.9 \pm 6.8$ & $5.8 \pm 0.5$ & 50.9 \\
\hline Control & $268.3 \pm 8.4$ & $255.4 \pm 8.8$ & $266.3 \pm 9.0$ & $264.4 \pm 8.2$ & $263.7 \pm 8.6$ & $-4.6 \pm 0.2$ & -59.6 \\
\hline
\end{tabular}

It was determined that in the control group of rats during the study period on the background of daily heat treatment there was a decrease in body weight, which was $4.6 \mathrm{~g}$ in average (or $59.6 \%$ of the body weight of intact rats) by the end of the experiment. Whereas the use of phytoglinol in the experimental groups contributed to the preservation of the gravimetric indicators of animals, with some fluctuations in the weight indicators (at the level of the trend). So, in the first experimental group (dose of injected preparation - 
$0.5 \mathrm{ml}$, duration 9 days), an increase in the body weight by $3.1 \mathrm{~g}$ was noted, in the second experimental group (dose of injected preparation $-0.25 \mathrm{ml}$, duration 9 days) it was $4.5 \mathrm{~g}$. The largest increase by $5.8 \mathrm{~g}$ was determined in the third experimental group, in which phytoglinol was injected at a dose of $0.5 \mathrm{ml}$ one hour before the heat treatment.

At the same time, the reliability of this effect was not statistically confirmed; therefore, we consider the absence of an additional stress factor in the first five days of the experimental period in connection with diagnostic manipulations (intramuscular injection) as a possible explanation, as indicated by the rather high level of weight gain in rats at the time of heat treatment.

According to the thermometry data, temperature fluctuations in the first and second experimental groups, in which phytoglinol was used prolonged, were recorded within the physiological norm, while in the third experimental group, an average temperature increase by $0.8{ }^{\circ} \mathrm{C}$ was noted (within the physiological norm). In the control group (with the use of saline), in the first three days of the experiment, the temperature fluctuations in the direction of increase were $1.2 \pm 0.1{ }^{\circ} \mathrm{C}$ in average, on the 4th day the differences between the temperature before and after heat treatment were $1.9 \pm 0,2{ }^{\circ} \mathrm{C}$ (table 3 ).

Table 3. Dynamics of body temperature in experimental animals under the heat stress $(\mathrm{M} \pm \mathrm{m})$

\begin{tabular}{|c|c|c|c|c|c|c|c|c|}
\hline \multirow{3}{*}{ Groups } & \multicolumn{8}{|c|}{ Temperature, ${ }^{\circ} \mathrm{C}$} \\
\hline & \multicolumn{2}{|c|}{1 day } & \multicolumn{2}{|c|}{2 day } & \multicolumn{2}{|c|}{3 day } & \multicolumn{2}{|c|}{4 day } \\
\hline & $\begin{array}{c}\text { Before heat } \\
\text { treatment }\end{array}$ & $\begin{array}{l}\text { After heat } \\
\text { treatment }\end{array}$ & $\begin{array}{c}\text { Before heat } \\
\text { treatment }\end{array}$ & $\begin{array}{l}\text { After heat } \\
\text { treatment }\end{array}$ & $\begin{array}{c}\text { Before heat } \\
\text { treatment }\end{array}$ & $\begin{array}{l}\text { After heat } \\
\text { treatment }\end{array}$ & $\begin{array}{c}\text { Before heat } \\
\text { treatment }\end{array}$ & \begin{tabular}{|c|}
$\begin{array}{c}\text { After } \\
\text { heat } \\
\text { treatment }\end{array}$ \\
\end{tabular} \\
\hline 1 Experimental & $38.2 \pm 0.6$ & $38.4 \pm 0.4$ & $37.5 \pm 0.3$ & $38.1 \pm 0.2$ & $38.4 \pm 0.3$ & $38.9 \pm 0.1$ & $37.6 \pm 0.1$ & $38.7 \pm 0.2$ \\
\hline 2 Experimental & $38.3 \pm 0.2$ & $38.7 \pm 0.2$ & $38.4 \pm 0.4$ & $39.0 \pm 0.1$ & $38.6 \pm 0.3$ & $38.4 \pm 0.2$ & $38.9 \pm 0.2$ & $38.6 \pm 0.1$ \\
\hline 3 Experimental & $37.7 \pm 0.1$ & $38.8 \pm 0.5$ & $39.1 \pm 0.3$ & $39.4 \pm 0.1$ & $38.4 \pm 0.1$ & $39.1 \pm 0.2$ & $38.4 \pm 0.2$ & $39.4 \pm 0.3$ \\
\hline Control & $38.3 \pm 0.2$ & $39.2 \pm 0.1$ & $38.1 \pm 0.5$ & $39.8 \pm 0.4$ & $37.9 \pm 0.5$ & $38.9 \pm 0.3$ & $38.2 \pm 0.4$ & $40.1 \pm 0.3$ \\
\hline
\end{tabular}

Based on the obtained data, it can be concluded that prolonged use of phytoglinol makes it possible to normalize the thermoregulation of the body, because under the stress, body temperature can rise significantly to high levels.

The development of stress syndrome in laboratory animals was characterized by the accumulation of lipid peroxidation products in the body - both primary (diene conjugates DC, ketodienes - KD) and secondary (malondialdehyde - MDA) and by a violation of the prooxidant-antioxidant balance, leading to damage of cell membranes and an increase in their permeability (table 4) [11].

The negative effect of the heat exposure on rats was accompanied by the activation of lipid peroxidation processes and the accumulation of peroxidation products in the blood an increase in the concentration of diene conjugates by $19.3 \%, 10.5 \%, 22.8 \%$ (experimental groups) and by $54.4 \%$ (control group) in relation to animals not participating in the heat treatment process and ketodienes by $26.5 \%, 32.4 \%, 23.5 \%$ and $47.1 \%$, respectively.

Table 4. Influence of phytoglinol on the state of antioxidant processes in the body of white rats under the heat stress $(\mathrm{M} \pm \mathrm{m} ; \mathrm{n}=5)$

\begin{tabular}{|l|c|c|c|c|c|}
\hline \multicolumn{1}{|c|}{ Parameters } & 1 Experimental & 2 Experimental & 3 Experimental & Control & Intact \\
\hline $\begin{array}{l}\mathrm{DC}_{(232)}, \\
\mathrm{AU} / \mathrm{mg} \text { lipids }\end{array}$ & $0.68 \pm 0.17$ & $0.63 \pm 0.33$ & $0.70 \pm 0.06$ & $0.88 \pm 0.13$ & $0.57 \pm 0.09$ \\
\hline $\begin{array}{l}\mathrm{KD}(273), \\
\mathrm{AU} / \mathrm{mg} \text { lipids }\end{array}$ & $0.43 \pm 0.12$ & $0.54 \pm 0.57$ & $0.42 \pm 0.02$ & $0.60 \pm 0.02$ & $0.34 \pm 0.04$ \\
\hline $\begin{array}{l}\mathrm{MDA}_{(537)}, \\
\mu \mathrm{M} / 1\end{array}$ & $1.87 \pm 0.12^{*}$ & $2.06 \pm 0.16^{*}$ & $2.12 \pm 0.25$ & $2.81 \pm 0.016$ & $2.46 \pm 0.011$ \\
\hline
\end{tabular}

Note: - differences are significant $* \mathrm{p}<0.05$ in comparison with the control group 
The concentration of malondialdehyde (MDA) increased only in the control group of rats by $14.2 \%$, while in the animals of the first two experimental groups, which received phytoglinol in various doses as a preventive course (5 days), the level of MDA decreased both in 1.5 and 1.36 times in relation to the control group, and it decreased in 1.32 and 1.2 times in relation to the intact rats. It should be noted that a similar picture was observed in the third experimental group, in which pharmacological correction with phytoglinol was carried out immediately before the heat treatment procedure, however, the amount of secondary decomposition products of polyunsaturated fatty acids in it was higher (by $13.2 \%$ in comparison with the first experimental group and by $2,9 \%$ in comparison with the second experimental group).

Analyzing the obtained data, it can be assumed that constant long-term exposure of high temperatures does not allow to stop the formation of primary lipid peroxidation products on the first line of the body's antioxidant defense, which, accumulating, increase the pool of diene conjugates and ketodienes in blood of the experimental animals. However, phytoglinol reliably prevents the accumulation of malondialdehyde in the body, which is currently considered as a marker of oxidative stress.

With the pharmacological correction of oxidative stress, it is important to assess the pathogenetic aspects of the body damage by toxic products of lipid peroxidation endotoxicosis of the body as a universal syndrome complex, the severity of which serves as criteria for the severity of the disease and predicting its outcome $[12,13]$. The syndrome of endogenous intoxication is caused by the accumulation of endotoxins in tissues and biological fluids - the so-called medium-mass molecules (MMM) or medium-molecular peptides (MMP) - under-oxidized products of both natural metabolism and those formed as a result of pathological conditions of the body. An essential feature of MMM is their distinctly high biological activity.

Therefore, at the end of the experiment, we evaluated the effect of high temperatures on the severity of endogenous intoxication syndrome in laboratory rats, assessed by the concentration of MMM in the blood of animals (Table 5).

Different wavelengths were used in the measurement: $237 \mathrm{~nm}$ (the result of a violation of intracellular homeostasis and the accumulation of secondary metabolites in excess such as hydrophobic toxins that have a high similarity to biological structures in plasma and in an almost completely bound state in the form of complexes with albumin or low density lipoproteins), $254 \mathrm{~nm}$ (MMM fractions accumulated the intermediate products of intense proteolysis - hormones, serotonin, fibrin degradation products) and $280 \mathrm{~nm}$ (MMM fractions accumulated the biologically active substances - aromatic residues (tryptophan, tyrosine, phenylalanine), heterocyclic (histidine) and sulfur-containing (cystine) amino acids) $[14,15]$.

Table 5. Influence of phytoglinol on the level of endogenous intoxication in the body of white rats under the heat stress $(\mathrm{M} \pm \mathrm{m} ; \mathrm{n}=5)$

\begin{tabular}{|l|c|c|c|c|c|}
\hline \multicolumn{1}{|c|}{ Parameters } & $\begin{array}{c}\mathbf{1} \\
\text { Experimental }\end{array}$ & $\begin{array}{c}\mathbf{2} \\
\text { Experimental }\end{array}$ & $\begin{array}{c}\mathbf{3} \\
\text { Experimental }\end{array}$ & Control & Intact \\
\hline $\begin{array}{l}\text { At 237 nm, } \\
\text { conventional units }\end{array}$ & $0.89 \pm 0.002$ & $0.79 \pm 0.012$ & $0.87 \pm 0.025$ & $0.98 \pm 0.13$ & $0.80 \pm 0.016$ \\
\hline $\begin{array}{l}\text { At } 254 \mathrm{~nm}, \\
\text { conventional units }\end{array}$ & $0.28 \pm 0.014$ & $0.28 \pm 0.018$ & $0.25 \pm 0.009 *$ & $0.32 \pm 0.015$ & $0.24 \pm 0.021$ \\
\hline $\begin{array}{l}\text { At 280 nm, } \\
\text { conventional units }\end{array}$ & $0.34 \pm 0.017$ & $0.25 \pm 0.013^{*}$ & $0.29 \pm 0.011$ & $0.38 \pm 0.010$ & $0.27 \pm 0.03$ \\
\hline
\end{tabular}

Note: - differences are significant $* \mathrm{p}<0.05$ in comparison with the control group

When carrying out measurements at a wavelength of MMM $\lambda=237 \mathrm{~nm}$, in two experimental groups (1st and 3rd) and control group, results were obtained that indicate an increase in the content of MMM after thermal treatment. However, the values of average 
molecular weight peptides in the experimental groups were close to those in intact rats and ranged from 1.2 to $10.1 \%$. Whereas in the group of control rats the increase in average mass molecules was $22.5 \%$.

When using wavelengths $\lambda=254$ and $280 \mathrm{~nm}$, the obtained data were similar - in all experimental groups there was a moderate increase in MMP, with the exception of the control, the values of which exceeded those of the intact group by 25.0-33.3\%. Although the data turned out to be reliable only when using the wavelength $\lambda=280 \mathrm{~nm}$.

The observed increases in the concentration of MMM in rats subjected to heat treatment may be due to the accumulation of proteolytic enzymes in blood, as well as catabolic processes and an increase in endogenous intoxication reactions accompanying the development of proteolysis of cell membranes under the action of aggressive peroxides.

Thus, the decrease in the concentration of various fractions of medium mass molecules in the blood of rats treated with phytoglinol correlates with the other laboratory tests carried out during the experiment and not only reflects the development of compensatory reactions aimed at restoring homeostasis, but also serves as a marker of the effectiveness of the therapy when activating the processes of free radical oxidation that occur on the background of stress loads on the body.

\section{Conclusion}

A preclinical experiment of the new veterinary preparation phytoglinol showed its positive effect on the organism systems of laboratory animals under the influence of stress factors, in particular, high temperature and humidity. Phytoglinol slows down the loss of body weight under the influence of heat stress, normalizes the body's thermoregulation, reduces the level of endotoxins of various origins in the blood of experienced rats, and activates the antioxidant defense of the body, which indicates the possibility of its use on productive animals in order to improve the quality of livestock products.

\section{References}

1. M. S. Atta, F. A. Farrag, E. A. Almadaly, H. A. Ghoneim, A. S. Hafez, S. K. Al Jaouni, S. A. Mousa, A. H. El-Far, Journal of Thermal Biology, 93, 102683 (2020)

2. L. F. Arantes de Souza, L. P. Espinha, E. Alves de Almeida, R. Lunedo, R. L. Furlan, M. Macari, Livestock Science, 192, 39-43 (2016)

3. G. Hoffmann, P. Herbut, S. Pinto, J. Heinicke, B. Kuhla, T. Amon, Biosystems Engineering, 10 (2019)

4. D. Belluzi, Dairy industry, 3, 87 (2010)

5. M. A. Bahry, H. Yang, P. V. Tran, P. H. Do, G. Han, H. M. Eltahan, V. S. Chowdhury, M. Furuse, Neuropeptides, 71, 90-96 (2018)

6. M. Al-Qaisi, E. A. Horst, E. J. Mayorga, B. M. Goetz, M. A. Abeyta, I. Yoon, L. L. Timms, J. A. Appuhamy, L. H. Baumgard, Journal of Dairy Science, 103(10), 96349645 (2020)

7. S. Khorsandi, A. Riasi, M. Khorvash, S. A. Mahyari, F. Mohammadpanah, F. Ahmadi, Livestock Science, 187, 146-150 (2016)

8. F. C. Cowley, D. G. Barber, A. V. Houlihan, D. P. Poppi, Journal of Dairy Science, 98(4), 2356-2368 (2015)

9. S. J. Hosseini-Vashan, M. Sharifian, A. H. Piray, M. H. Fathi-Nasri, Animal Feed Science and Technology, 267, 114553 (2020) 
10. K. F. Sullivan, T. L. Mader, Veterinary Clinics of North America: Food Animal Practice, 34(2), 325-339 (2018)

11. A. A. Abramov, E. P. Dolgov, L. I. Yakusheva, E. V. Kuzminova, M. P. Semenenko, N. V. Kovaluk, K. A. Semenenko, IOP Conference Series: Earth and Environmental Science 52037 (2020) doi: 10.1088/1755-1315/421/5/052037

12. J. R. Nelson, M. M. A. Ibrahim, E. B. Sobotik, G. Athrey, G S. Archer, Livestock Science, 240, 104149 (2020)

13. H. D. G. Mogollón, R. A. Ferrazza, V. H. Vallejo, F. C. Destro, J. C. Ochoa, C. Nogueira, R. F. Carvalho, L. N. Moraes, G. Rizzoto, R. Sartori, M. C. Wiltbank, J. C. P.Ferreira, Journal of Dairy Science, 103(6), 5629-5633 (2020)

14. B. M. Shahar, L. Li A. G. Javaid, G. Wang, Journal of Thermal Biology, 61, 82-90 (2016)

15. M. P. Semenenko, E. V. Kuzminova, E. V. Tyapkina, A. A. Abramov, K. A. Semenenko, Journal of Pharmaceutical Sciences and Research 9(9), 1573-1575 (2017) 